\title{
ANALISIS PERSEPSI SISWA PADA MATERI KOLOID DALAM PEMBELAJARAN KIMIA DENGAN MENGGUNAKAN MENTAL IMAGE ANALYSIS OF STUDENT'S
}

\author{
Dyah Ratna Wulandari, Marheni, Nurbaity \\ Jurusan Kimia, Fakultas Matematika dan Ilmu Pengetahuan Alam, Universitas Negeri Jakarta, Jl. Pemuda 10 \\ Rawamangun Jakarta 13220 Indonesia
}

Corresponding author: dyah.dydy21@gmail.com

\begin{abstract}
Abstrak
Penggambaran makroskopis, mikroskopis dan simbol dalam mata pelajaran kimia yang disebut sebagai triangle levels of representations dapat membuat persepsi siswa terhadap konsep menjadi berbeda-beda dan ada kemungkinan mengalami miskonsepsi atau kesalahan konsep. Visualisasi dapat memperjelas persepsi atau mental image siswa mengenai gambaran suatu konsep yang ada dalam pikirannya. Pada pembelajaran materi koloid selama ini disampaikan dengan analogi secara verbal, sehingga dapat menimbulkan persepsi siswa yang berbeda-beda terhadap suatu konsep. Diharapkan jika terdapat kesalahan persepsi (miskonsepsi) pada siswa, maka akan dapat dideteksi lebih awal dengan menggunakan mental image. Tujuan penelitian ini adalah untuk mengetahui persepsi siswa terhadap konsep-konsep dalam materi koloid dengan menggunakan mental image. Penelitian dilaksanakan di SMA Negeri 1 Tangerang pada bulan Mei-Juni 2013. Metode yang digunakan adalah metode deskriptif analisis. Sampel dalam penelitian ini adalah siswa kelas XI IPA 1 dan XI IPA 2. Hasil penelitian menunjukkan bahwa sebagian besar siswa masih mengalami miskonsepsi pada beberapa konsep pada materi koloid.
\end{abstract}

Kata kunci: miskonsepsi, koloid, mental image

\begin{abstract}
Macroscopic, microscopic and symbol representation in chemistry which is stated as triangle levels of representations can make student's perceptions of concept become different and there is possibility of misconception. Visualization can clarify perceptions or student's mental image about representation of a concept in student's mind. Colloid is taught by verbal analogy that can make different student's perceptions about a concept. If there is misconception, it can be detected earlier by using mental image. This study is implemented at SMA Negeri 1 Tangerang in May-June 2013. Method that used is analysis descriptive. This study samples are students of XI IPA 1 dan XI IPA 2. Study results show that most of students have misconception about some colloid concepts.
\end{abstract}

Keywords: Student's perceptions, colloid, mental image

\section{Pendahuluan}

Pada umumnya, pelajaran Kimia bersifat abstrak. Siswa harus memiliki pemahaman konseptual dalam Kimia yang mencakup kemampuan dalam menggambarkan dan menerjemahkan permasalahan Kimia dengan menggunakan gambaran makroskopis, mikroskopis dan simbol ${ }^{[1]}$. Penggambaran makroskopis, mikroskopis dan simbol dalam mata pelajaran kimia yang disebut sebagai triangle levels of representations dapat membuat persepsi siswa terhadap konsep menjadi berbeda-beda. Persepsi adalah proses mental melalui pengamatan atau pemberian makna yang menghasilkan bayangan individu (penafsiran)

sehingga dapat memberikan tanggapan mengenai baik buruknya hal tersebut ${ }^{[2]}$. Persepsi yang berbeda-beda memungkinkan terjadinya miskonsepsi atau kesalahan konsep. Miskonsepsi ini dapat berupa kesalahan dalam mengkonstruksi konsep yang diterima pada saat pembelajaran yang diakibatkan oleh pengalaman, lingkungan, ataupun kemampuan siswa itu sendiri. Seorang siswa dapat dikatakan mengalami miskonsepsi jika konsep yang mereka 
miliki tidak sesuai dengan konsep yang dimiliki oleh para ahli[ ${ }^{[2]}$. Hal ini didukung oleh Novak yang mendefinisikan miskonsepsi sebuagai suatu interpretasi konsep-konsep dalam suatu pernyataan yang tidak dapat diterima ${ }^{[3]}$. Masalah terbesar berkaitan dengan miskonsepsi adalah sekali miskonsepsi tersebut terjadi maka hal tersebut akan sulit untuk diubah dan akan berakibat serius pada pembelajaran ${ }^{[4]}$. Miskonsepsi sangat sulit untuk diubah ${ }^{[5]}$. Oleh sebab itu, miskonsepsi pada siswa harus diminimalisir.

Untuk menarik minat siswa mempelajari Kimia dan menghindarkan mereka dari miskonsepsi, dalam proses pembelajaran saat ini telah banyak menggunakan analogi yang sesuai dengan konsep. Penggunaan analogi ini dapat membantu siswa dalam memvisualisasikan konsep Kimia yang abstrak dengan kehidupan nyata sehingga siswa dapat dengan mudah memperoleh konsep yang benar. Analogi dapat membantu siswa dalam mendapatkan konsep yang lebih bermakna sehingga lebih mudah diingat dan tidak mudah dilupakan. Terdapat dua jenis analogi dalam pembelajaran, yakni analogi fisik (visual) dan analogi verbal ${ }^{[6]}$. Saat ini banyak analogi yang dibuat oleh guru. Analogi ini dapat menghasilkan cara pandang yang berbeda bagi setiap siswa dan dapat menghasilkan konsep yang salah pada diri siswa.

Visualisasi memang dapat membantu siswa dalam belajar, namun untuk menghindari persepsi yang salah (miskonsepsi), lebih baik siswa itu sendiri yang melakukan analogi visualisasi karena tidak ada proses belajar yang lebih baik dibandingkan dengan melakukannya sendiri ${ }^{[7]}$. Visualisasi dapat memperjelas persepsi atau mental image siswa mengenai gambaran suatu konsep yang ada dalam pikirannya. Melalui mental image ini, siswa dapat mengekspresikan konsep Kimia. Mental image ini dapat mengindikasikan apa yang tidak dipelajari secara baik, miskonsepsi yang belum diketahui, dan pemahaman mereka mengenai konsep Kimia ${ }^{[7]}$.
Pada pembelajaran materi Koloid, selama ini disampaikan dengan analogi secara verbal, sehingga dapat menimbulkan persepsi siswa yang berbeda-beda. Diharapkan jika terdapat kesalahan persepsi (miskonsepsi) pada siswa, maka akan dapat dideteksi lebih awal dengan menggunakan mental image. Oleh karena itu, dilakukan analisis terhadap persepsi siswa pada materi koloid dalam pembelajaran Kimia dengan menggunakan mental image.

\section{Metodologi Penelitian}

Metode yang digunakan adalah metode deskriptif analisis. Sampel penelitian ini adalah siswa kelas XI IPA 1 dan XI IPA 2 SMAN 1 Kota Tangerang. Instrumen yang digunakan dalam penelitian ini adalah soal esai sebagai fokus pertanyaan sebagai panduan untuk membuat gambar mengenai apa yang ada dalam pikiran siswa dan rubrik penilaian mental image siswa. Rubrik yang digunakan adalah rubrik analitik. Digunakan juga instrumen validasi ahli untuk mengetahui bagaimana penilaian ahli terhadap rubrik dan soal yang akan digunakan. Instrumen tersebut adalah lembar penilaian yang menggunakan skala Guttman ${ }^{[8]}$. Reliabilitas yang digunakan adalah uji reliabilitas antar rater Intraclass Correlation Coefficient (ICC) dari Fleiss Kappa ${ }^{[9]}$. Setelah didapatkan nilai ratarata kesepakatan antar rater, nilai tersebut dibandingkan dengan nilai kategori kesepakatan menurut Fleiss.

Pengambilan data dilakukan dengan menilai menggunakan rubrik mental image yang telah dibuat siswa dari hasil penugasan akhir dengan rentangan skor antara 1 hingga 4 . Skor 4 merupakan skor maksimal yang menunjukkan bahwa siswa sudah menguasai konsep. Teknik ini dilakukan dengan memberikan tugas yang menggambarkan mental image siswa secara individual mengenai konsep yang terdapat dalam materi koloid.

\section{Hasil dan Pembahasan}


Berdasarkan uji validitas ahli, rubrik dan soal yang telah dibuat adalah valid dengan persentasi 96,88\%, masuk ke dalam kategori sangat baik. Hasil untuk reliabilitas antar raternya dengan menggunakan rumus larutan tersebut tanpa bantuan mikroskop. Siswa telah memahami ukuran partikel antara larutan sejati, koloid, dan suspensi adalah berbeda. Siswa juga telah mampu mengurutkan ukurannya yakni ukuran partikel terlarut dari Inritan oninti Inhih lenal dari uluiran nortilenl

Tabel 1. Data skor mental image pada setiap konsep

\begin{tabular}{|c|c|c|c|c|c|c|c|c|c|}
\hline \multirow{2}{*}{ Indikator } & \multicolumn{3}{|c|}{1} & \multicolumn{2}{|c|}{2} & \multirow{2}{*}{3} & 4 & 5 & 6 \\
\cline { 2 - 10 } & $\mathrm{a}$ & $\mathrm{b}$ & $\mathrm{c}$ & $\mathrm{a}$ & $\mathrm{b}$ & & \\
\hline $\begin{array}{c}\text { Total } \\
\text { Responden } \\
\text { yang menjawab }\end{array}$ & 58 & 58 & 58 & 46 & 46 & 56 & 56 & 30 & 11 \\
\hline Skor 4 & $0,00 \%$ & $0,00 \%$ & $0,00 \%$ & $84,78 \%$ & $34,78 \%$ & $1,79 \%$ & $8,93 \%$ & $46,67 \%$ & $9,09 \%$ \\
\hline Skor 3 & $0,00 \%$ & $0,00 \%$ & $10,34 \%$ & $15,22 \%$ & $47,83 \%$ & $0,00 \%$ & $21,43 \%$ & $26,67 \%$ & $63,64 \%$ \\
\hline Skor 2 & $91,38 \%$ & $32,76 \%$ & $0,00 \%$ & $0,00 \%$ & $15,22 \%$ & $16,07 \%$ & $10,71 \%$ & $6,67 \%$ & $9,09 \%$ \\
\hline Skor 1 & $8,62 \%$ & $67,24 \%$ & $89,66 \%$ & $0,00 \%$ & $2,17 \%$ & $82,14 \%$ & $58,93 \%$ & $20,00 \%$ & $18,18 \%$ \\
\hline
\end{tabular}

Intraclass Correlation Coefficient (ICC) menunjukkan bahwa rata-rata kesepakatan antar rater masuk dalam kategori sangat baik sebab nilai rata-rata koefisien kesepakatan antar raternya 0,9536.

Persepsi siswa dilihat berdasarkan hasil gambar siswa yang diberikan skor sesuai dengan rubrik yang telah dibuat. Soal yang diberikan terdiri dari 6 butir soal dimana siswa diminta untuk memilih 4 butir soal untuk digambarkan.

Pada soal nomor 1 siswa diminta untuk menggambarkan perbedaan larutan sejati, koloid, dan suspensi sehingga dapat dilihat persepsi siswa melalui mental image tentang 3 konsep dalam materi koloid, yakni ukuran partikel (a) zat terdispersi (b) dan medium pendispersi (c). Sebanyak 58 orang dari 64 orang siswa menjawab soal nomor 1 . Untuk ukuran partikel, sebanyak 53 orang atau 91,38\% siswa mendapatkan skor 2 yang menunjukkan hampir seluruh siswa memiliki gambaran ukuran partikel larutan sejati lebih kecil dari ukuran partikel koloid dan ukuran partikel koloid lebih kecil dari ukuran partikel suspensi. Namun, mereka berasumsi bahwa mereka dapat melihat partikel dari ketiga jenis terdispersi pada koloid lebih kecil dari ukuran partikel terlarut pada suspensi. Namun, seluruh siswa masih mengalami miskonsepsi mengenai mikroskopik. Mereka menggambarkan seolaholah seluruh partikel pada ketiga jenis larutan tersebut dapat dilihat langsung tanpa bantuan alat seperti mikroskop sebagaimana ditunjukkan oleh jawaban salah satu siswa pada gambar 1.
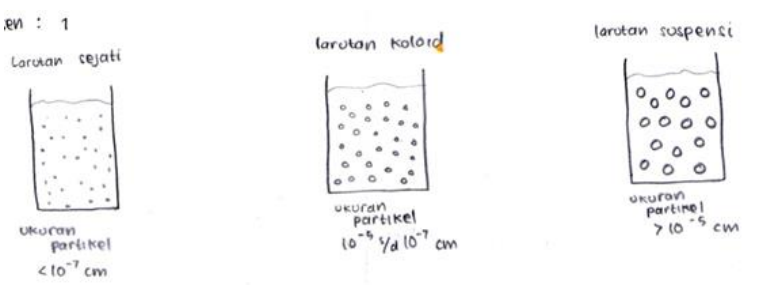

Gambar 1. Jawaban Siswa Soal Nomor 1 (skor 2 untuk ukuran partikel)

Berkaitan dengan pertanyaan nomor 1 untuk zat terdispersi, sebanyak 39 orang atau $67,24 \%$ siswa mendapatkan skor 1 yang menunjukkan bahwa siswa memiliki gambaran mengenai partikel terlarut pada suspensi sama seperti partikel terdispersi pada koloid, tidak mengalami pengendapan. Hal ini menunjukkan bahwa sebagian siswa belum memahami 
mengenai efek gravitasi terhadap partikelpartikel dalam larutan sejati, koloid, dan suspensi dengan baik. Siswa tersebut dikatakan mengalami miskonsepsi karena beranggapan bahwa partikel-partikel terlarut pada suspensi tidak terpengaruh oleh gaya gravitasi, sama

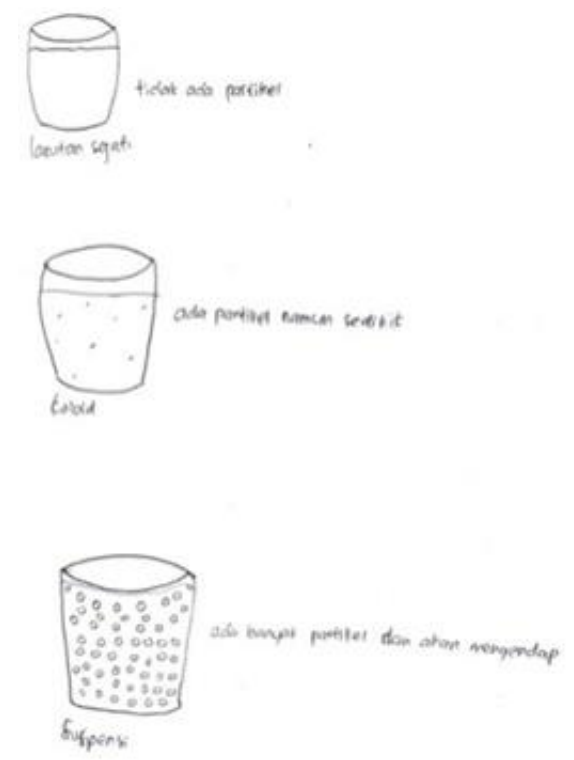

Gambar 2. Jawaban Siswa Soal Nomor 1 (skor 1 untuk zat terdispersi)

dengan partikel-partikel terlarut pada larutan sejati maupun partikel-partikel terdispersi pada koloid sebagaimana digambarkan oleh salah satu siswa pada gambar 2. Untuk medium pendispersi pada soal nomor 1, 52 orang atau $89,66 \%$ siswa mendapatkan skor 1 yang menunjukkan bahwa hampir seluruh siswa tidak memiliki gambaran mengenai partikel dari medium pendispersi pada larutan sejati, koloid, maupun suspensi. Hal ini menunjukkan bahwa hampir semua siswa mengalami miskonsepsi mengenai partikel pelarut pada setiap jenis larutan. Mereka mengganggap bahwa hanya ada partikel terlarut atau terdispersi pada setiap larutan. Hanya sebagian kecil siswa yang menggambarkan partikel pelarut atau pendispersi sebagaimana gambar salah satu siswa pada gambar 3.
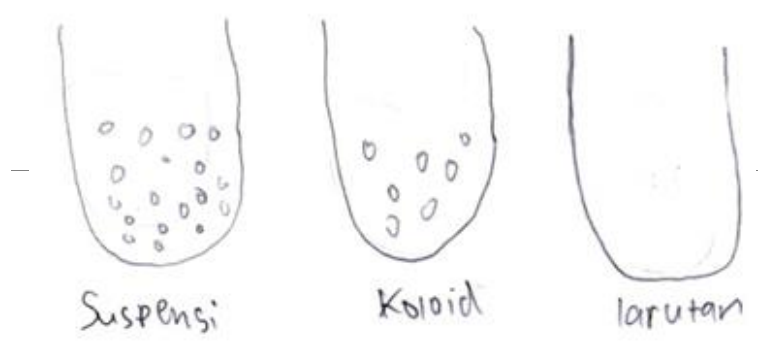

Gambar 3. Jawaban Siswa Soal Nomor 1 (skor 1 untuk medium pendispersi)

Pada soal nomor 2 siswa diminta untuk menggambarkan salah satu contoh koloid dalam kehidupan sehari-hari sehingga dapat dilihat persepsi siswa melalui mental image mereka tentang 2 konsep dalam materi koloid, yakni aplikasinya dalam kehidupan sehari-hari (a) dan jenis koloid (b). Sebanyak 46 orang siswa dari 64 orang siswa menjawab soal nomor 2. Untuk aplikasi koloid dalam kehidupan sehari-hari, terdapat 39 orang atau $84,78 \%$ siswa yang dapat menggambarkan 1 contoh koloid serta benar dalam menggambarkan medium pendispersi dan zat terdispersinya. Siswa tersebut mendapatkan skor 4. Hal ini menunjukkan bahwa hampir semua siswa tidak mengalami miskonsepsi karena sudah memahami submateri contoh koloid dalam kehidupan sehari-hari sebagaimana digambarkan salah satu siswa pada gambar 4 .

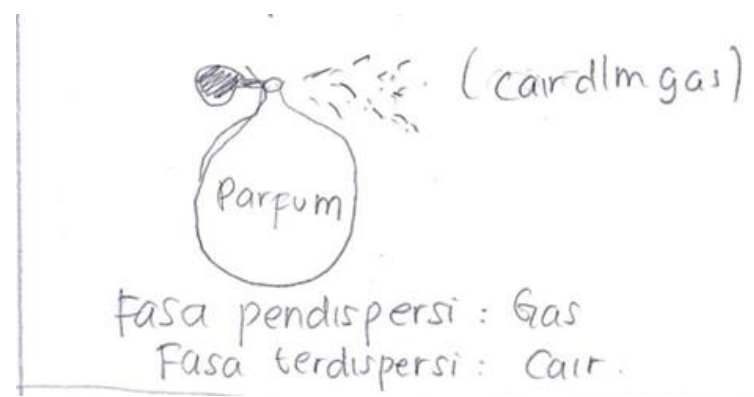

Gambar 4. Jawaban Siswa Soal Nomor 2 (skor 4 untuk aplikasi koloid dalam kehidupan sehari-hari)

Sedangkan untuk jenis koloid pada soal nomor 2 , terdapat 22 orang atau $47,83 \%$ siswa benar dalam menggambarkan medium pendispersi dan zat terdispersinya namun secara terpisah sehingga mendapatkan skor 3. Hal ini menunjukkan bahwa sebagian siswa tidak mengalami miskonsepsi karena sudah 
memahami jenis terdispersi dan pendispersi dari suatu sistem koloid, namun mereka belum memahami bahwa sistem koloid terbentuk jika fase terdispersi dan pendispersinya berada dalam satu sistem. Jika berdiri sendiri bukan sistem koloid sebagaimana gambar salah satu siswa pada gambar 5 .

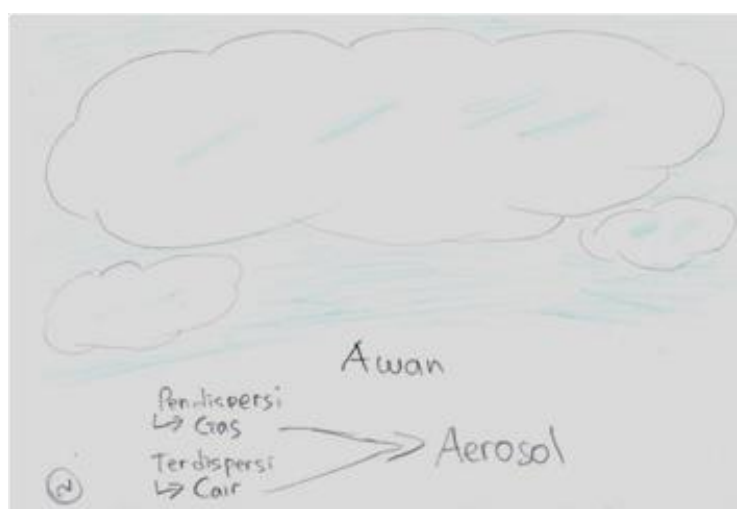

Gambar 5. Jawaban Siswa untuk Soal Nomor 2 (skor 3 untuk jenis koloid)

Pada soal nomor 3 siswa diminta untuk menggambarkan Efek Tyndall sehingga dapat dilihat persepsi siswa melalui mental image yang dimilikinya tentang Efek Tyndall. Sebanyak 56 orang siswa dari 64 orang siswa menjawab soal nomor 3. Terdapat 46 orang atau $82,14 \%$ siswa mendapatkan skor 1 karena hanya menggambarkan sinar melewati sistem koloid. Hal ini menunjukkan bahwa sebagian besar siswa mengalami miskonsepsi karena beranggapan ketika suatu sinar melewati sistem koloid yang terjadi hanyalah sinar yang melewati koloid, tidak ada sinar yang dipantulkan oleh partikel-partikel terdispersi koloid sebagaimana digambarkan oleh salah satu siswa pada gambar 6 .
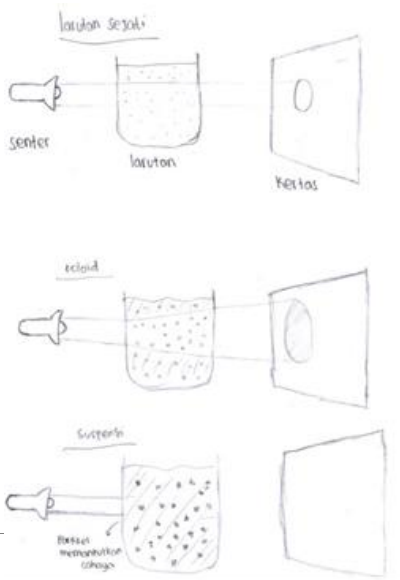

Gambar 6. Jawaban Siswa untuk Soal Nomor 3 (skor 1 untuk efek Tyndall)

Pada soal nomor 4 siswa diminta untuk menggambarkan Gerak Brown sehingga dapat dilihat persepsi siswa melalui mental image yang dimilikinya tentang Gerak Brown. Sebanyak 56 orang siswa dari 64 orang siswa menjawab soal nomor 4 . Terdapat 33 orang atau 58,93\% siswa yang mendapatkan skor 1 karena hanya menggambarkan satu partikel koloid mengalami gerakan zig-zag. Hal ini menunjukkan bahwa sebagian besar siswa mengalami miskonsepsi karena beranggapan hanya 1 partikel koloid saja yang mengalami gerakan zigzag. Secara tidak langsung menggambarkan bahwa dalam suatu sistem koloid hanya terdapat satu partikel sebagaimana digambarkan oleh salah satu siswa pada gambar 7 .

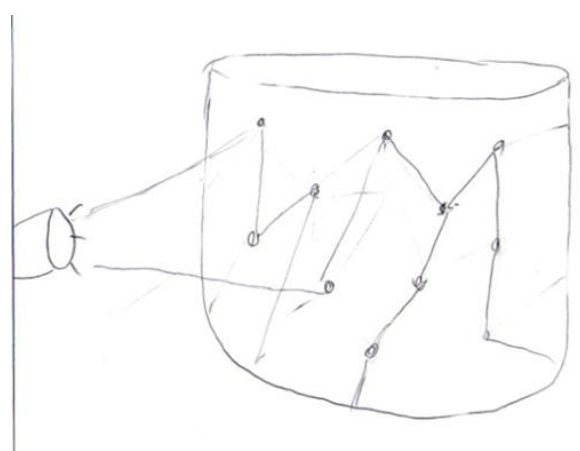

Gambar 7. Jawaban Siswa Soal Nomor 4 (skor 1 untuk gerak Brown)

Pada soal nomor 5 siswa diminta untuk menggambarkan proses pembentukan delta sungai sehingga dapat dilihat persepsi siswa melalui mental image yang dimilikinya tentang koagulasi. Sebanyak 30 orang siswa dari 64 orang siswa menjawab soal nomor 5 . Sebanyak 14 orang atau $46,67 \%$ siswa mendapatkan skor 4 karena dapat menggambarkan partikel yang bermuatan negatif mengadsorpsi partikel yang bermuatan positif atau sebaliknya kemudian mengendap secara mikroskopis. Hal ini menunjukkan bahwa sebagian siswa tidak 
mengalami miskonsepsi karena sudah mampu menggambarkan proses adsorpsi yang terjadi hingga terbentuknya endapan pada peristiwa pembentukan delta sungai. Siswa tersebut dapat memahami proses yang terjadi pada pembentukan delta sungai dan memahami bahwa delta sungai terjadi di daerah pertemuan air sungai dengan air laut sebagaimana digambarkan oleh salah satu siswa pada gambar 8 .

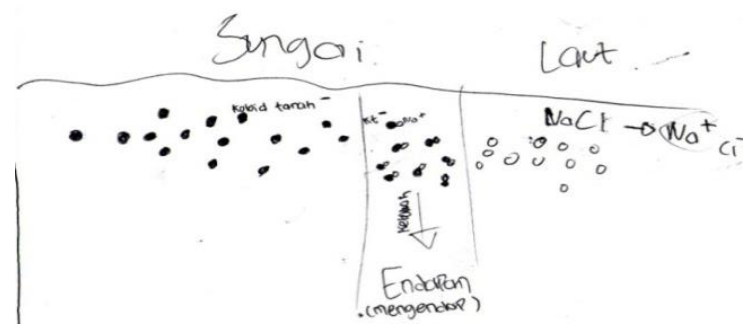

Gambar 8. Jawaban Siswa Soal Nomor 5 (skor 4 untuk koagulasi)

Pada soal nomor 6 siswa diminta untuk menggambarkan proses pembekuan darah sehingga dapat dilihat persepsi siswa melalui mental image yang dimiliki tentang adsorpsi. Sebanyak 11 orang siswa dari 64 orang siswa menjawab soal nomor 6 . Terdapat 7 orang atau $63,64 \%$ siswa yang menggambarkan partikel yang bermuatan negatif mengadsorpsi partikel yang bermuatan positif atau sebaliknya secara mikroskopis. Hal ini menunjukkan bahwa sebagian besar siswa yang menjawab soal ini tidak mengalami miskonsepsi, namun hanya dapat menggambarkan sampai terjadinya adsorbs pada proses pembekuan darah. Sedikit sekali dari siswa yang menjawab yang dapat menggambarkan hingga terjadinya darah yang membeku seperti yang digambarkan oleh salah satu siswa pada gambar 9 .

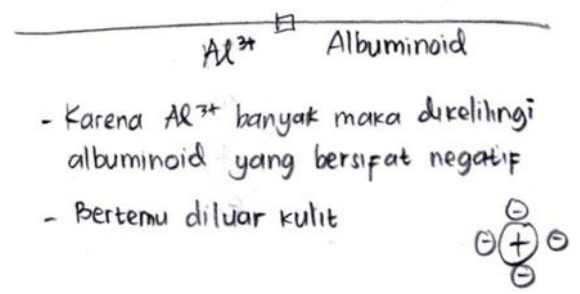

Gambar 9. Jawaban Siswa Soal Nomor 6 (skor 3 untuk adsorpsi)

\section{Kesimpulan}

Berdasarkan hasil analisis persepsi siswa pada materi koloid dalam pembelajaran kimia dengan menggunakan mental image dapat disimpulkan bahwa siswa mengalami miskonsepsi pada konsep partikel mikroskopik, endapan pada suspensi, partikel terdispersi atau pelarut, Efek Tyndall, dan Gerak Brown. Sedangkan konsep-konsep yang belum dipahami oleh siswa adalah ukuran partikel koloid, larutan sejati, dan suspensi, konsep campuran koloid (partikel pendispersi dan terdispersi digambarkan dalam keadaan terpisah), serta pada konsep adsorpsi. Konsep yang sudah dipahami oleh siswa adalah aplikasi koloid dalam kehidupan sehari-hari dan koagulasi.

\section{Penghargaan}

Kami ingin berterima kasih kepada Jurusan Kimia FMIPA Universitas Negeri Jakarta atas kesempatannya untuk menyusun makalah dalam jurnal ini. 


\section{Daftar Pustaka}

[1] Mahaffy, Peter, Chemistry Education: Research and Practice, (2004) 5(3) 229-245.

[2] Wulandari, Dyah Ratna; Marheni; \& Nurbaity, (2013), Analisis Persepsi Siswa pada Materi Koloid dalam Pembelajaran Kimia dengan Menggunakan Mental Image, Jakarta: FMIPA UNJ.

[3] Suparno, Paul. (2005). Miskonsepsi dan Perubahan Konsep dalam Pendidikan Fisika. Jakarta : PT Grasindo. Hal. 5, 53

[4] Thompson, Fiona \& Logue, Sue, International Education Journal, (2006) 7(4) 553-559.

[5] Yuruk, N, J Sci Educ Technol, (2007) 16 515-523.

[6] Dagher, Z. R., J. Res. Sci. Teach., (1995) 32 259-270.

[7] Mirzaie, R. A., Eurasian J. Phys. Chem. Educ. (2010) 2(1) 53-62.

[8] Sugiyono, (2012), Metode Penelitian Pendidikan (Pendekatan Kuantitatif, Kualitatif, dan R\&D), Bandung: Alfabeta. Cet. Ke-15 Hal.139, 147

[9] Wuensch, K. L. 2007. Inter-Rater Agreement. Core.Ecu.Edu/Psyc/Wuenschk/.../Inte rrater.Doc 